\section{THE PRESENT POSITION OF SOME CELL PROBLEMS.}

DURING the last two decades or so a new branch of science has been quietly, but rapidly, working its way from a position of comparative obscurity to one of considerable importance. This new-comer has been designated Cytolugy, and it embraces as its province that department of knowledge which centres around the cell, whether this body be regarded from its structural or from its functional aspect. And cytology, which is still a young offshoot both from botany and zonlogy, pos. sesses one strongly marked advantage. viz. that of providing a common ground on which the botanist and the zoologist may still meet to di-cuss questions of equal interest to each. For in dealing with the cell we are approaching facts and phenomena which are essentially shared or exhibited by animals and plants alike, and, indeed, the measure of therr relative importance can be gauged by the degree in which they reappear in each of the two great divisions of organic life; although in most other respects the animals and plants have followed widely diverging paths of development.

The cell was long ago recoenised as the structural unit of an organism, but the relations of its various parts to one another were overlooked or misunclerstond, and we are still far from arriving at a satisfactory solution of the difficulties which each investigator meets when attacking the problems presented by any special case; nevertheless, some general facts hatve been discovered which serve as landinarks to guide future exploration.

In all but the very lowest forms of life, and in some other which are probably degenerate, we recognise clearly enough that the protoplasm of an organism contains one or more nuclei within its substance. Commonly, though by no means in variably, each nucleus is associated with a definite mass of pro. toplasm which is segregated, mure or less strictly, from the rest by means of membranous partitions. These partitions are not, however, necessarily always present. Some animals, and many of the lower plants, possess a protoplasm in which are distributed large numbers of nuclei, which thus appear to lie embedded in a common matrix. Instances of this are seen in Vaucheria and in the embryonic stages of Periparus. But although the nuclei are thus scattered, there is a considerable body of evidence to show that their respective spheres of influence are tolerably clearly defined, just as are those of different countries, even when these are not delimited ly obvious boundaries like rivers or mountain ranges.

On the other hand, just as there are roads and traffic between two neighbouring countries, 50 it has been shown by several observers that even where the "cells" are separated by walls from each other, the adjacent protoplasms are often connected by fine threads of the living substance which traverse the intervening cell walls. The phenomenon seems to have been occasionally seen without apparently its importance being realised. but Tangl clearly demonstrated it for plant celis (Endosperm) almost twenty years ago. Since that time the investigations of Gardiner, Kienitz-Gerloff, and others have shown that what were once thought to be merely isolated cases may possibly turn out to form rather the rule than the exception. There can be but little doubt that the improved uranium-osmium method of Kolossow, which has recently been employed with considerable success by Gardiner, will materially extend our knowledge in this direction, and will confirm what most of us have for a long time held, that the difference between such a plant as Caulerpa and the ordinary multicellular forms is rather one of degree, the result of specialisation, than one of kind. Thus during the germination of some algre, certain of the Fucacere for example, the embryo exists for a considerable time in a multinucleate condition, the cell walls only appearing at a later stage. The same is also seen during the development of the endosperm in a fowering plant, and still more strikingly during the germination of the spore of Isoetes or of Selayinella. The occurrence of a stage in the developinent of many plant tissues, during which the constituent cellis are sliding past each other in adjacent rows, is seen to furnish no real argument for a protoplasmic discortinuity at this period, when it is remembered that not only are the walls still soft, but that they actually contain a nitrogenous body which is almost certainly protoplasm in their substance. On the animal side also evidence is not lacking to show that in some of the higher forms, at least in the earlier stages; protoplasmic continuity is of frequent occurrence ; and it also oltains, according to Schuberg and others, between the cells of some tissues in the adult animal.
Nevertheless, the want of such a continuity in nerves, e.g. in the gangtionic cells, suffices to show that it is unsafe to generalise on $d$ pxiori grounds too freely, for it is in nerves, perhaps more than in most other tissues, that a direct continuity might have been expected. And it is the more necessary to emphasise the lesson derived from a study of the histology of nervous tissues, inasmuch as a continuity of protoplasm has been generally assumed to exist in the tissues of motile organs of plants, on purely physiological grounds, although it may not have been demonstrated histologically.

The role played by the nucleus in influencing or in deter. mining the mode of special activity manifested by its attendant protoplasm is one of great interest, and a great deal of light has been thrown upon it within recent years. Haberlandt and others have clearly shown that in cases where metabolism was more active in one region of the cell than in another, the nucleus commonly migrates to this locality Beautiful examples of this may be observed during the thickening of the walls so frequently met with in the protective layer of seeds or fruits. Thus if the development of the seed of the cominon night-shade (Solanum Dusliamara) be followed, it will be seen that in the young stages of the large cells which ultimately give rise to the hard shell of the seed, the nucleus occupies a central position. Later on, the nucleus becomes lodged in close proximity to the inner wall of the cell, and this then begins to thicken. This deposition of thickening substances spreads to the lower (or inner) parts of the lateral walls; whilst their outer portions, as well as the whole of the external wall, which is remote from the nucleus, remains thin. Again, it has been observed by Istvanffi that when the hypha of a fungus is about to branch, the nucleus is discoverable at a spot just beneath which the outgrowth is about to arise.

The well-known and highly characteristic appearance of the large nuclei met with in tissues the cells of which are in an active state of division, is all evidence of the important infuence of these bodies over the process. So also is the fact that those cells which are the last to lose the faculty of resuming an embryonic condition (i.e. of giving rise to fresh tissues) retain these nuclear peculiarities longest. This point is well brought out in a study of the cells of a growing root, for it is easily seen that those which form the layer known as the pericycle keep the primitive appearance of their nuclei the longest, and it is in this layer that the new structures, the lateral roots, when they occur do actually originate. Again, when new structures are about to be formed from tissues already adult, or even senescent, the first obvious sign of the new impulse is detected in a change in the nuclei of the cells, a change which depends as much on chemical as on physical differences. In cells which are secreting, whether belonging to animals or to plants, the nuclei are observed to pass through a remarkable series of changes, which may even result in the temporary differentiation of the peculiar so-called chromatic elements, resembling if indeed not identical with those appearing during nuclear division. Much the same is to be seen in the huge nuclei often present in the "foot cells" in an animal testis, around which the young immature spermatozoids cluster in groups, apparently deriving from the chemical activity of these cells the nourishment requisite for the completion of their development.

Even more conclusive evidence as to the close relation between the metabolism of the external protoplasm (conveniently distinguished as cytoplasm) and the nucleus is furnished by the different behaviour of nucleated and non-nucleated fraginents of protoplasm respectively. It is quite possible, by taking appro. priate measures, to vivisect a single cell, so that one portion shall contain a nucleus and the other not. The former half commonly regenerates itself, and if derived from a plant cell, forms around itself a new cell wall; on the other hand, the non-nucleated fragment sonner or later perishes, although it may continue for a time to exhibit normal vital functions. Usually, however, it is able neither to secrete on its surface a membrane, nor to engage on constructive metabolism.

But interesting and suggestive as are the relations which can be discerned between the cytoplasm and the nuclei of cells in a condition of comparative repose, they are alnost eclipsed by the wonderful series of changes which recur with surprising uniformity each time the nucleus and the cell divides. Nor is it always easy currectly to estinate the relative importance of the various structural elements which are involved or concerned in the process.

Of late years we have heard a great deal about a minute 
particle which is present, sometimes in the nuclets, oftener in the external cytoplasm, and which is by many assumed to play the part of a directive agent in the matter of nuclear division. This body, known as the Centrosome, was first brought into prominence by the researches of Van Beneden on the developing eggs of Ascaris, and it has since been recognised in an enormous number of animals, and also in the cells of some plants.

The centrosome is frequently a body of extraordinary minute ness, and it is most easily recognised during certain stages of nuclear division, on account of the central position which it occupies with respect to the radiations which acconpany the process.

It has, howerer, been identified in many cells which are in a state of repose, as a minute particle which may or may not be surrounded by differentiated zones of specialised protoplasm, though it is certain that in many cases this appearance is due merely to a diffraction-phenomenon. Furthermore, it is not unfrequently observed that its division precedes any change in the nucleus, and that when the division of this latter body is approaching, the two daughter centrosomes diverge from each other, each situated in a definite protoplasmic nuass and forming one of the two poles of the spindle structure which arises during the process of karyokinesis." Sometimes, indeed, this spindle structure is seen to be spun out, as it were, between the two centrosomes at the moment of their separation, and to grow as they move further apart. liven more important, perhaps, than these olservations was the statement made by Fol, that cluring the process of fertilisation both the male and female cell contributed a distinct centrosome, each of which then divided and the half of the onc then fused with the corresponding hal of the other, a proceeding to which he gave the name of the Quadrille of the Centrosomes. This statement, which wa supported by preciscly similar statements on the part of Guignarel for plants, as well as by other zoologists, has, however, proved to be due to misinterpreted or mistaken observation. It is quite certain that at present there is no really authenticated example of such a procecding occurring either in plants or in animals, although a glance at many modern text-bonks testifies to the nold which these erroneous accounts have taken on receptive minsls.

In the enthusiasm to which the first discovery of the centro some, and its subsequent identification in so many kinds of cells, gave birth, it has not alway's perhaps been sufficiently remen. bered that post hoc by no means necessarily implies propter hoc, and that neither its reappearance at the period of karyokinetic activity, nor yel its observed persistence through the resting stage in some cells, are of thenselves sufficient to establish its claims to be regarded as the primary directive agent in bringing about a nuclear division. Supposing, however, that it could be shown to be really possessed of all the nccult powers which have been claimed for it by its numerous devotees, the main result would be to remove $t 0$ an immeasurably sreater distance all chance of penetrating more deeply into the mysteries of cell life. For its very minuteness renders it almost immune from the critical gaze of the curious.

Possibly some light may be thrown on the method of action (if indeed it really possesses any at all) of this enigmatical body, by a consideration of some of the cases in which it cannot be said to exist at all. For some years past it has been known (and the number of examples has been recently muliplied) that in certain plants the nuclear division is not inaugurated by the appearance of two diverging centrosomes, which could occupy a definite position with regard to the radiations at this time visible in the protoplasin. On the contrary, radiations start out from many centres in the cell, and run in various directions, though with a general tendency towards the nucleus. Later on these numerous centres become, so to speak, polarised, and commonly come together at two principal points occupying opposite ends of the cell. Thus a final condition of affairs is reached, resembling the more regular arrangement obtained by the centrosome mechanism (Figs. I and 2). What starts these radiations in the first instance? It is difficult to imagine them to be otherwise than due to a chemical change in the protoplasm or of some of its included substances, and this view is strengthened by the observations made by Iertwig and others on the stimulating and modifying action of drugs, such as quinine or strychnine. Morgan, by merely altering the salinity of the sea-

1 A word used to signify nuclear division, introduced by Schleicher; it is exuivalent to the term. Ifitosis, empluyed by Flemming. water, was able to produce centrosomes and radiations at will, and the irregularity in number and siee which they displayed was just such as might have been expected, on the hypothesis here advanced.

These observations- and many similar ones could be citedgo to show that the impulse 10 division, which some have triec? i) identify exclusively with the centrosome, is more probably dependent on the condition of the protoplasm as a whole. It is quite probable that, as in so many other cases, the stimulus may be at bottom a chemical one, connected with the elaloration of some substance producing the disturbances which result in the formation of the machinery for cell tivision. It is even possible that the sulstance may, in the more specialised cells, or in those of rapidly dividing tissues, be agrgegated into a mass which assume's the manifold appearance that one finds in the centrosomes, centrospheres, and so on. From what we know of protoplasm it would hardly be surprising if this were so. Carbohydrate can be stored as starch, to be again lost to sight as sugar, de. ; why not the substance which may be supposer? to be capable of reacting with the rest of the protoplasm in the
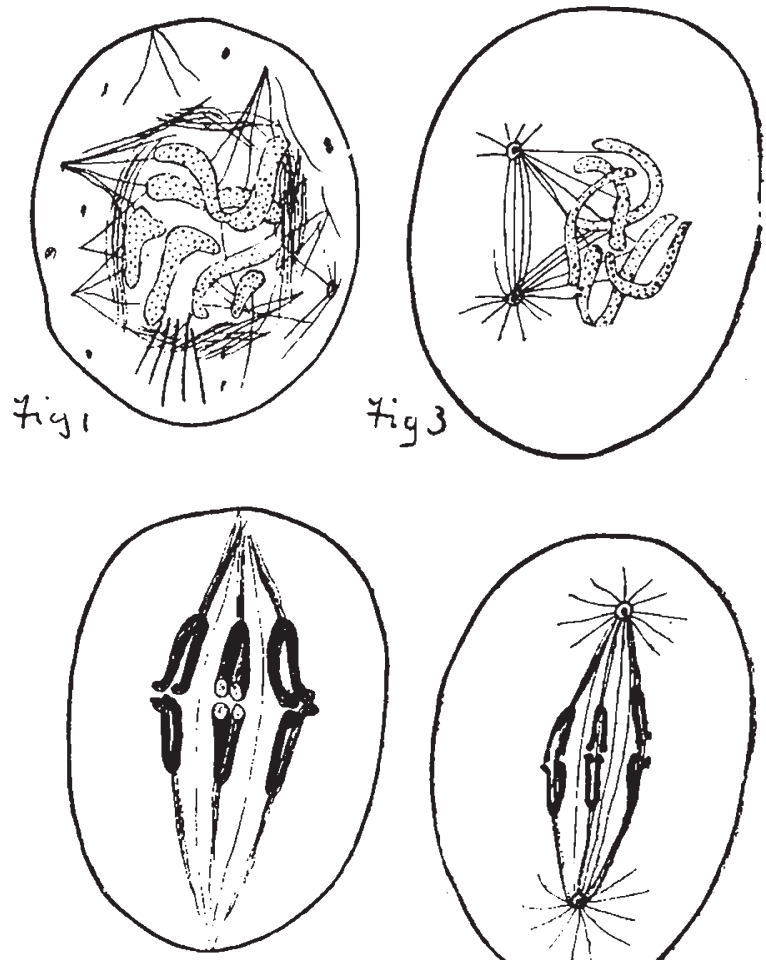

Tig. 2

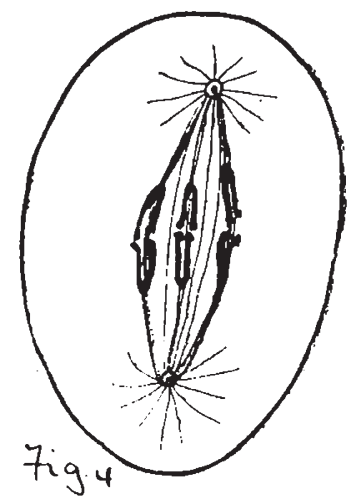

production of the karyokinetic phenonena? But this is a very different thing from considering the centrosome as a sort of autocrat presiding over the destinics of the cell, as its more enthusiastic supporters have claimesl. It wonld not even be necessarily a permanent structure inaugurating the cell changes, but would represent a sulsstance, which might merely be formed ad hoc, and which, after the period of activity, might either lose its identity--sinking to the general level of the substances containerl in the protoplasm--or if present, in sufficient quantity, over and above what proved to be needed for a given occasion, it might remain as a formed substance to be used up later.

Thore is a large body of evidence to show that, when present, it is intimately associated with the processes of nuclear division, though whether in an active or passive connection it is difficult, perhaps impossible, to say. Certainly, taking the most farourable view as to its autocratic powers, it can effect nothing unless the protoplasm be ready to receive it. The centrosome of a spermatozoid introluced into a ripe egg may become the centre of a system of radiations, but none are produced if the ovun ,happens to be immature. And on the whole, especially in vicis 
of the behaviour of those cells in which nu centrosomes have been discovered in spite of infinite toil having been spent on the attempt to prove their existence, it seems more probable that they are not to be regarded as morphological structures ranking with nuclei or plastids, but at most as consisting of matter which may be condensed to a granular form, or which may be present or be manufactured in a state diffused through the protoplasm. Indeed this inatter may perhaps not be in: appropitately compared with zymogens, which, when suitably acted upon, liberate substances capable of exerting an influence altogether incommensurable with their amount on materials within the scope of their power. But no one would probably go so far as to elevate a lunp of zymogen, if it could be shown to exist in a given cell or tissue, to the rank of a celi organ, any more than most people regard the elatorated spindle fibres as representing anything but a specialised phase of protoplasmic structure, at most temporarily differentiated from the rest of the cell substance, and destined, sooner or later, to le re-alssorbed into it, although the remains of some spindles persist long after the cells in which they were formed (de novo) have completed their division.

Having briefly glanced at the centrosome, we may pass on to consider some of the more important peculiarities connected with the actual process of division of the nucieus. And, first, we will consider the mode of the formation and division of those remarkable structures-the clirum:sonies. During its resting state, a nucleus presents a granular or spongy appeararce, and is commonly seen to contain one or more refractive bodies-the nucleoli. $\Lambda$ s the stages of aproroching division are passed through. a substance (which can be identified also in the resting state), known as the chromatin, begins to assume a growing importance. This substance, which consists largely of nucleic acid, aggregates along more or less definite tracts of the colourless and less stainable matrix (linin) within the nucleus, and finally nearly all the linin is used to provide a substratum in which the chromatin is embedded. This linin scaffolding as. sumes the appearance of a much convoluted thread or threads, and, owing to the predominance of the chromatin, its existence is easily (and often) overlorked. The thread then shortens and thickens, and eventually breaks transversely into a definite number of segments constant for the particular species. IIeantime the well-known spindle is formed, and the chromosomes become arrayed around it (Figs. 2, 4). They are now seen to split longitudinally, and finally the two halves separate, passing to opposite ends of the spindle, where they help to reconstitute the daughter-nuclei which arise in this way. Now, since the original chromatin containing thread appears to be symmetrical about its long axis, it is clear that there exists no obvious grounds for assuming that the two groups of chromosomes, which have ultimately arisen as the result of a Inngitudinal fission of this thread, represent anything but the reffected images of each wher; and indeed there is a great deal which strongly suggests that the significance of the complicated stages passed through, lies in the ensuring of a qualitatively equal distribution of naterial to each of the two daughter cells; guantitative equality is also secured far more accurately than would probably be the case if each chromosome divided transversely instead of longitudinally.

The reappearance of a definite number of chromosomes, as well as a priori considerations, based on the relations which on good grounds believed to obtain between the chromo. somes and the existence of hereditary qualities in an organism, have led many investigators to believe that they are the same chromosomes which constantly reappear at each karyokinetic period; although, in the majority of instances, they cannot be recognised in the intervening state of rest between the successive divisions. This view is, perhaps, hardly sufficiently warranted by the facts, and some of its warmest supporters have been obliged to take refuge in expressions such as a "physiological persistence"; a sort of persistence which may be entertained as a pious opinion, but which, when one tries to rigorously define it, proves as elusive as metaphors usually are.

But the chief interest which centres in the chromosomes depends on the remarkable part played by these bodies in connection with the reproductive processes. Since every act of fertilisation consists essentially in the union of two cells and of their contained nuclei, it is clear that the resulting nucleus will possess twice as many chromosomes as that in each of the cells which have fused together. And if this is repeated in consecu. tive generations it is obvious that the chromosomes, increasing in geometrical progression, will soon becomie too, numerous to be contained within the limits of any one nucleus. Hence the necessity of a reduction in their number at some period between each act of fertilisation. This reduction regularly occurs, and always happens at a definite period in the history of the organism, ilthough the exact epoch may differ considerably in different groups of plants or animals.

A considerable discussion has arisen as to the exact significance to be attached to the process, over and above the bare fact of the halving of the number of the chromosomes. Some have tried to show that variation, so characteristic of animals and plants, is ensured by the distribution of entire chromosones between the two daughter-nuclei; others have seen in it a return to an "embryonic condition" which renders the act of fertilisation a necessary antecedent to further development; others, including Strasburger, whilst recognising that it is preparatory to lertilisation, and that it indirectly promotes variation by rendering the fusion with another cell possible, regard it as the expression of a return to an ancestral condition. which prevailed before fertilisation by the union of two individuals had come into existence. Of the explanations here mentioned the first is the most consistent, or at least is, at first sight, less obviously contradicted by facts than the rest. But, nevertheless, it will be seen that it does not by any means embrace all the well worked-out cases, and therefore cannot be considered as of general application. It will, however, be specially considered here, because it is so often brought forward as a most important argument in support of Weismann's theory of Heredity.

Weismann, as is well known, regarded the hereditary qualities of an individual as closely bound up with certain cellular structures, and he has identified these with the minute particles of chromatin which in the aggregate go to form a chromosome. Each chromusome is conceived of as possessing the material substrata for all the specific characters of the urganism, but, the arrangement or constitution of these is slightly different in the different chromosomes. The actual course of development, followed by the organism as a whole, depends on the degree, in which one or other group of characters becomes predominant, or on the result of a compronise between them.

Clearly, therefore, whilst an organism which had lost half its chromosomes could not be expected to exhibit as many possibilities of variation as one which retained its full number (if development were possible at all under such circumstances); by the elimination of the half, and subsequent replacement of them by corresponding (but slightly differing), chromosomes from another individual, the chances of new variation would certainly, if we accept the premises, be greatly increased.

These views have been worked out in great detail, and they have received quite a remarkable confirmation as the result of the researches of Riickert, Häcker, vom Rath, and others. But, whilst recognising the great interest attaching to the results obtained by these investigations, it is at present quite.impossible to regard them as affording more than a local confirmation of Weismann's theories, simply because, although they may possibly bear this interpretation, there are (as already indicated) other cases which even Procrustes himself could not fit into the same bed.

As regards the general character of the "reduction divisions," there naturally exists a certain amount of variety in detail; but in the following summary an attempt will be made to present the more salient and lundamental features of the pro. cess. If one takes as an example a higher aninal, the reduction divisions are seen to be closely related with the formation of the actual sexual cells-ova and spermatozoa; up to the penultimate divisions the line of cell generations have possessed nuclei with a definite number of chromosomes, which we will designate as $2 n$. Then follows a long period of repose and of gruwth, and when the nuclei of these cells emerge from their quiescent condition, the number of their contained chromosomes is seen nut to be $2 n$, but only $n$. That is to say that a numerical reduction has, somehow, been accomplished in the resting period. There is no question here of any chromosomes having been eliminated, nothing has been expelled (so far as can be seen) from the nucleus, but there has been a rearrangement. It has been suggested, and the riew is stoutly maintained by Hacker and others, that the reduction here is only apparent, and that what has really occurred is that the original thread has only, so to speak, broken transversely at. every other joint, leaving two chromo. somes attached end to end. Each appaient chromosome then 
sould be really double. Be this as it may, these chromosome behave essentially like those of other preceding cells as regards their fission, dividing longitudinally, as before. But the process is here very complicated, and it is only as the result of very many and careful researches that this fact has been definitely ascertained. Quite apart from the altered (reduced) numbers of the actual chromosomes present, the course of their development deviates sn widely from the normal type of karyokinesis in whatever the animal or plant one may happen to be investigating, that it has been designated by Flemming as the Heterotype ${ }^{1}$ division.

It has alteady been stated that some writers hold that no true reduction has occurred at this period, and by them (Häcker, Riirkert, \&.c.), it is termed a pseudo-reduction, for they consider that in the next, and rapidly following, division the real reduction occurs. In the latter division it is belicved, in the cuses investigated, which belong chiefly to the Arthropoda, that a real gualitalnae reduction occurs by the splitting transversely of each of the pseudo-chromosomes, and by the distribution of the halies thus produced to the two datighter-nuclei. In other words, the two genuine chromosomes which remain united as a pseudo-chromosome during the heterotype karyokinesis, now separate from each other, and thus each daughier-nucleus receives half the number of original entire chromosomes, and conseguently con:es to contain slightly different sets of hereditary potentialities. Ifowever this may he for Arthropoda, in which the process is by no means easy to follow, it is certain, as the researches of Meves, conducted under the auspices of Flemning, clearly prove, that such a sorting of chromersones does not occur during the development of the sexual cclls of Salamander, trut that the second (and last), like the heterotype division preseding it, passes through a Iongitudinal-fission stage. And it is equally celtain that the saine is true, at least, filr the higher plants. Ischikawa's recent results with Allizm, which secn to point to a contrary conclusion, can hardly be admitled as evidence one way or arother, since, judlering from his oren account of the pro. cess, he seems to rave mi:understrod the slagts with witich he was dealing. And in any case, the existence of numernus exactly worked out examples in which a transwerse fissinn certainly does not occur, nhviously disposes of any attenupt to make it serve as the basis for a general thenry of the mechanism by which variation may' he supposed io be secured.

In spite of all the efforts which have been made, we are still without a certain clue in the meaning of the reduction. Unquestionably Wismann's view, which has been supported by Häcker and others, offers the most attractive solution of the puzzle; but, as has been pointed out, it clearly will not explain the facts in all cases. Others believe the essential feature to lie in the sudden reduction in the amount of chromatin consequent on two so rapidly consecutive divisions But the divisions do not invariably' succeed each nther with no interven. ing period of rest. Strasburger has suggested that it represents a return to an ancestral pre-fertilisation state, and it is possible that there may he found io lee some probability for this. But against it is to be set the quevtion why organisms with different numbers of chromosomes in their nuclei always halie that number, whatever it may happon in be, and do nut all come to possess a commion number of reduced, and consequently of duplicated chromosomes, for cren clocely related forms often differ widely in this respect. However we explain it, it seems clear that no theory which dependis on the continued per. manence of chromosumes can be admitted. Fach one of the reduced number canrot be conipounded of twn original ones, as such, but must be a new structure ; clse it is obvious that we have no real reduction at all, but only a series of pseudo-reductions -a view which would soon land us into an impossible position. But if the chromosomes are not really permanent structures, then the whole process of the two divisions of which we are speaking, resolves itself into a mechanism which, whilst provid. ing for a halving, provides equally for an accurate distribution of the halved substance between the two final daughter-nuclei.

1 The chief differences which distinguish the heterotype from other divicions lies in $(\alpha)$ tbe long period of gruwth prepitration; $(\beta)$ the relatively early appearance of longleudinal tission in the chromatic thread; $(\gamma)$ the frenuent separation of the halves thus formed at this early stage, and their subsequent approximation to one another of the halves in a variety of mans, hefore they become grouped on the spindle; $(\delta)$ the curious and very characteristic appearance of the mature chromosomes on the spindle, some. times taking that of closed rings, with (commonly) local equatorial thicken. ing, or the cl romosonie an this stage may', in some forms, assume the form of four spheres. lonsely held together, constituting the vierer f'usfo of the German authors.

No. I 490 . VOL. 58 ]
And although the acceptance of such a view of the matter would involve a modification of those opinions shared by many as to the nature of the architectural configuration of the hereditary substance, in accordance with which discrete particles of it are commonly assumed to be associated with definite hereditary qualities, still the alternative hypothesis by no means negatives the possibility of regarding heredity as the outcome of the constitution of some such substance taken as a whole. The qualities of the organism would depend on the structure of the material basis, just as the structure of a crystal-to use an old illustration - depends on the ultimate configuration of the constituent mole. cules. An analogy of this sort is perhaps not worth much-it is a comparison of a relatively simple with an infinitely complex case--but still we are more likely to make a definite advance by arguing, even imperfectly, from (hings of which we know some. thing. than by abandoning ourselves to phantasies which are intangible, and consequuently incontestible.

During the course of a nuclear clivision, there are few phenomena which are more striking than the genesis and mode of operation of that extraordinary structure known as the achronatic spindle. This body provides the framework for the whole process, as well as the machinery by which it is effected. It originates in many different ways, and exhibits various degrees of perfection in different organisms; but the ultimate result attained is much the same in all.

Two extreme types of its modes of origin may be briefly out lined. In the less perfect form, as the period of nuclear division is about to commence, radiations are seen to start out in the protoplasm. Sometimes these are connected with the nucleus itself, lsut more often they seem to be ficussed in groups in inany of the granules with which, at this starc, the protoplasm is fillec.. But there is nos sort of order in their arrangement. Later on it is seen, however, that the lines become gradually and with increasing rapidity frocussed to two opposite spots in the cell, and then the normal spindle is fully formed. It is idle here to speak of the existence of centrosomes as initiating a process which thus begins so irregularly, and the assuniption that they are really secretly existent all the time, and by their hidden activity cause the astral radiations to converge to the two proles, suggests if not a fetztio principii, at least a revelation derived from sone source from which nere mundane minds are debarred.

In the mote perfectly formed mechanism, the spindle originates from a definite mass of protoplasm which is intimately related to centrosomes, and consequently it only is formed in this manner when these structures are actually present.

It appears to be, so to speak, spun out between the diverging centrosomes, and either to pass into a gronve in the nucleus, or to rope up towards itself the chromosomes which by this lime are clifferentiating. But whatever be the manner of its origin, when it is fully formed it provides a structure upon which the chromosones are arrayed, and upon which, after the separation of the wo halves into which they severally split, the daughter chroninsomes travel to the respecijue poles. In many cases additional fibres can be distinculished which have become attached to these retreating hodies, and thus, by contracting, drag them towards the two ends of the spindle.

The advantage, mechanically speaking, of two poles to which all the achromatic fibres running between them converge, is clearly recongnised during the changing conditions of stress and strain which occur during the course of a karyokinesis, and it serves to throw some light on certain phenomena which have attracted less attention than they seem to descrve.

Hitherto the poles have been treated of here as though they were nnly marked by the convergence of the nuclear spindle fibres; but, over and above these, there are numerous other fitres which radiate into the cell protoplasm, and which may even reach the cell wall. Now, it is a significant lact that these radiations are nost apparent during the first formation of the spindle and during the end phases of division, i.e. whilst the daughter chromosonies are being pulled up to the poles. Often, as in germinating spores of Pellia (a liverwort), they entirely dic away in the interval separating these $t$ wo stages. The wholc appearance strongly suggests that the function of these radia. tions, differentiated out of the cytoplasm, is to steady the poles, and thus render the achromatic framework a rigid one. Indeed withnut some such arrangement it is difficult, if one watches the process going on, to imagine how the necessary stability would be secured.

When the chromosomes have reached their respective 
destinations, and whilst they are gradually forming into the daughter-nuclei, a curious change usually occurs at the equator of the spindle in the fibres which still stretch acruss the intervening space between the two poles. The threads become more numerous and present over the area mentioned a thickening of their substance, and by the fusion of the swellings a cell wall, dividing the original cell into tho halves, may be formed. And whilst this is happening, there is evidence to show that the fibres themselves, which become strongly arched, are in a state of compression and thus the young wall is stretcher to its utmost exient. The plane of equilibrium within the spindle depends on the shape of the cell; and thus at first, and whilst still plastic, one can predict what position it will

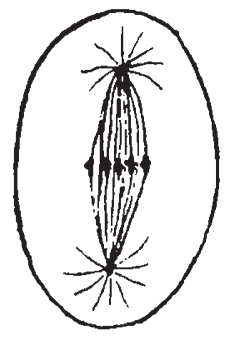

Fig. 5
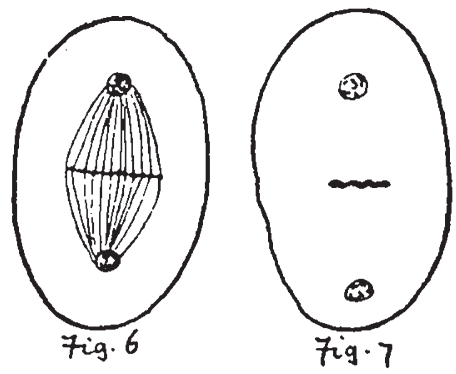

take up as regards the existing bountlaries of the cell. Indeer the resemblance of such a nascent wall to a soap film has struck more than one investigator, and has been worked out in some detail by Wildemann.

The general relalion of cell division to mechanical conditions is well illustrated during the development of pollen cells. In the monocutyledon: the original pollen-mother-cell gives rise io the pollen grain; by 1 wo succeeding divisions with an interval of rest between them. The first karyokinesis is followed by a jar. titioning of the cell, which is thus divided into two symmetrical halves, niten hemispheres. When the latter finally divide, they also are symmetrically partitioned, though this, of course, can (and usually (nes) happen by means of walls which are not similarly orientated in both of the two first formed cells. In Dicotyledons, on the orher hand, in which also there are two sucesssive biparti. tions of the nucleus, the appearance of the cell walls is deferres until the full nuinber (fuur) of nuclei has been proluced. And, just as night have been expected, the way in which the aciual partitioning takes place is consequently modified. If spherical, as is cummonly the case, the quadrinucleated cell is simullane. ously divirjed ints four tetrahedral cells by walls converging to the centre at an angle of $60^{\circ}$.

It would be difficult to find an example which more strongly witnesse's to the influence of the form of the cell as governin:

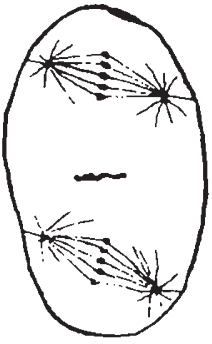

$7 i g .8$

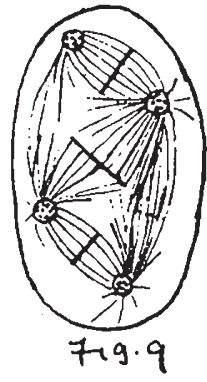

the disposition of the walls which partition it, than is furnisherl by the spore formation of a common liverwort. Fesalella contiar. And as it also iliustrates some other points touched upon in the preceding pages, this paper may be fitly brought to a close by a description of the more salient peculiarities attendant on the process. The spare-mother-cell, which ultimately gives rice to four spores, is shaped like an nval box tiattened above and below. When its nucleus divides (Fig. 5 ), the (wo) daughter.nuclei lie in the line of its major axis, and a rudimentary cell wall begins to be formed at the ecjuator of the spindle (Fig. 6), after the fashion already indicated above. But, unlike most structures of this kind, it does not extend to the peripheral walls owing, apparently, to the relatively small size of the spindle. As the Iwo) daughter-nuclei pass into the resting condition, the spindle fibres die away, and an interesting change comes over the character of the uncompleted division-wall. It ceases to be stretched out, and becomes somewhat crumpled and obvionsly thicker, whilst its area correspondingly diminishes (Fig. 7).

Then, after a time, the two daughter-nuclei again divide (Fig. 8), and after this division, resulting in the production of four nuclei, preparations for the real partitioning of the cell begins. What ever position they may hase previously occupied, the nuclei now take up that shown in Figs. 4 and 11 ; and they are apparently compelled to do so by the action of the radiations, which exterd from each one of them inlo the surrounding cytoplasm. Whilst they are settling down to their final positions. the uriginal cell-plate, above spoken of, is caused to rotate through an angle of $30^{\circ}$, so that it now is parallel with, instead of at right angles to, the major axis of the elliptical cell. Its molion is clearly seen to be the result of a directive action on the part of the highly developerl systems of racliating fibres, and when it has iurned round it is seen 10$)^{\circ}$ have lost its thick crumpled appearance, and to have become thin and tence. As suon as it has ceased to cut across the line of protoplaim between the nuclei belonging to opposite pairs, the radiations are seen to arrange theinselves into a spindle form, just like that formed between the daughter-nuclei of each pair, a fact of considierable theoretical importance in the elucidation of the genesis of spindle struclures generally. In the equators of these two newly differentiated spindles, as in each of the two normal ones, cellplates are formed, four in all, and they become altached in pairs to the ends of the primary plate, now lying longitudinally in the cell (see Figs. 9 and 10 ), and thas the partition of the space is completed (Fig. Il). A proint of special interest in
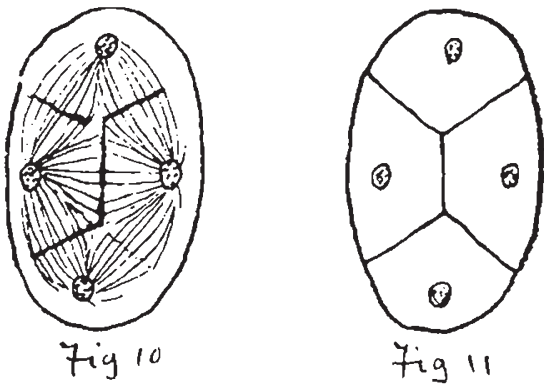

this case of Fegatella lies in the remarkable fact that we here meet with two perlectly different conditions of cell divi-ion, and that the transition from the one 60 the other can lef followed in every stage. Theoretical requirements are here demonstrably satisfied in a manner such as we can seldism he..pe 10 equal in uur altempts in sulve the many problems :vith which

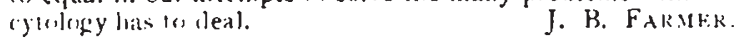

\section{VASCO IIA GAMAI}

$\mathrm{WF}$, are assembled this evening 10 commemorate one of the greatest events in the history of the world - the discovery of the ocean route to India by the P'ortuguese. Vasco da (jama completed the mighty enterprise on the day when the ghits of Inclia were sighted from the deck of his ship just four hundred vears ago to morrow. The credit-of this cliscovery is due to the Portuguese pesple, to their constancy and heroic perseverance, even mure than to the skill and ability s! their leaders; and 1 think that many of the illustrious navigators of Portugal are cqual in merit, and should be equal in renown. We contemplate the perseverance of this people and the continuity of their work during a century and a half of mighty effort, rather than a single strnke of genius. Fet it is right that Vasco da Gaina, "ho forged the last link, should have the first place which Camoens has assigned to him, primus imter pares.

Prince Henry gave the first impelus, and during a quarter of a century he created a school of ranen who rounded Cape Bojador in 1435, Cape Blanco in 1443. Cape Verde in 1445, and

1 Acldrens delivered befure the Riyal Geogiaph ca "ociety, ob May 16, by the I'resident.

NO. I 490, VOL. 58] 